\title{
O desempenho escolar dos filhos na percepção de pais de alunos com sucesso e insucesso escolar
}

\author{
Valéria Aparecida Chechia \\ Antônio dos Santos Andrade \\ Universidade de São Paulo
}

\begin{abstract}
Resumo
Neste artigo investigam-se as percepções de pais sobre o desempenho escolar dos seus filhos, analisando o conteúdo de entrevistas semi-estruturadas com 32 pais, sendo dezesseis pais de alunos com desempenho classificado como sucesso e demais pais de alunos com insucesso escolar. Quanto ao desempenho escolar, tanto os pais de alunos com sucesso, como os de insucesso atribuem razões relacionadas à responsabilidade do filho, do professor e também às da própria família. Os resultados permitem evidenciar que tanto uns quanto outros revelam que a família deve promover a valorização da escola e de auxílio às tarefas, bem como a escola precisa rever os seus valores e procedimentos em relação ao aluno e à família. Assim, destacamos a necessidade de os pais serem mais bem orientados pela escola para poderem assessorar seus filhos. Estratégias sugeridas pela escola, ou outros pais, podem auxiliar pais que, por trabalharem, não possam estar presentes na escola.

Palavras-Chave: rendimento escolar; relação família-escola; ensino fundamental
\end{abstract}

\begin{abstract}
The children's school performance in the perception of parents of students with school success and school failure. This article examines parents' perceptions of children's school performance, by analyzing the contents of semi-structured interviews with 32 parents, grouped in sixteen parents of students with performance classified as successful and, in the other half, parents of students with school failure. As for school performance, both groups attribute responsibilities to the child, to the teacher and also to the family itself. The results for both groups reveal that the family should promote valorization of school and of homework assistance, and also that school needs to revise its values and procedures concerning students and their families. So, we emphasize the need of parents being better oriented by school so that they can help their children. Strategies suggested by school, or by other parents, may help parents who, because of their work, can not be present at school.
\end{abstract}

Keywords: school performance; family-school relationship; fundamental teaching

$\mathrm{N}$ os estudos desenvolvidos a respeito do envolvimento dos pais na vida escolar dos filhos, tem sido particularmente relevante o fenômeno da relação dos pais com o rendimento escolar dos filhos e a percepção que constroem sobre a escola. Neste contexto, realizou-se uma pesquisa com pais de alunos com sucesso e insucesso escolar que teve como objetivo geral conhecer as percepções dos pais sobre a escola, o desempenho escolar de seus filhos e o envolvimento deles próprios no cotidiano escolar. O presente artigo trata da percepção que os pais constroem sobre o desempenho escolar dos filhos.

Vários fatores podem ser determinantes do sucesso e do insucesso escolar, na visão da família e da escola. Uma posição recorrente no pensamento da escola é a que fomenta discursos, centrando a indisciplina como um fator resultante do tipo de contexto familiar. Considera-se ainda que, em muitos casos, os pais interferem negativamente na vida escolar, o que acaba prejudicando o comportamento em sala de aula. Neste sentido, para a escola, os pais não têm apenas que estar presentes, mas devem também assumir o papel ativo no cotidiano escolar dos filhos. O apoio e a participação dos pais na vida escolar dos filhos colaboram com a escola no sentido de se obter um trabalho de classe mais equilibrado.

Certamente a (in)disciplina é algo que vai além da utilização ou não de um padrão ou modelo instituído pela família, sendo também característica de contextos que desenvolvem regras de disciplina, como é o caso da escola (Collett, Gimpel, Greenson, \& Gunderson, 2002). Um outro aspecto que pode 
influenciar no desempenho escolar é a adaptação à escola. Observamos que ela parece estar relacionada a uma interação família-escola. Lippitz e Levering (2002) advertem quanto à necessidade de que família fortaleça o conhecimento e o significado de escola para a criança e que a escola possa confirmar esses significados e conhecimentos.

No que se refere às relações conceituais entre indisciplina, adaptação escolar e contexto familiar há necessidade de se dizer que essa é uma temática para discussão que pode contribuir para uma mudança no discurso ideológico da família e da escola. É possível que muitos comportamentos adquiridos no cotidiano familiar sejam generalizados para o cotidiano escolar. Por um lado a escola tende a justificar suas incertezas atribuindo as dificuldades que enfrenta somente à família, por outro e cada vez mais freqüente, deparamos com famílias que esperam por soluções que acreditam devam ser da escola. Assim, estão sendo produzidas crenças centradas apenas na questão da influência familiar para as ações cotidianas dos alunos na escola, desviando a atenção daquilo que a escola pode e tem condições de resolver, por exemplo, em relação às regras e à disciplina.

Segundo Szymanski (1997), escola e família são instituições que têm em comum a preparação das crianças para a sua futura inserção na sociedade. A família é uma instituição em transição como outras tantas em nossa sociedade, o que é natural em uma sociedade em progresso. A família parece estar procurando se ajustar aos novos movimentos e ideários sociais, o que nos parece perfeitamente normal. Se compararmos a família de hoje com a de dez anos atrás, observaremos diferenças, mas não necessariamente desequilíbrio.

Carvalho (2000) levanta uma questão muito interessante, afirmando que se insistirmos no discurso de que a família tem de dar assessoria, tem de ajudar em casa, como ficam aquelas famílias cujas mães não têm essa possibilidade, não têm cabedal cultural para isso e nem disponibilidade de tempo? Então, essas crianças estariam fadadas ao insucesso escolar? Numa sociedade que, atualmente, defende a participação intensa da família na escola, as crianças cujas famílias não se enquadram nessa expectativa, certamente sofrem conseqüências negativas por parte dos professores.

Para Carvalho (2000), o aluno deve ser preparado de acordo com o seu contexto e a escola deve aprender a conviver com as diferenças e as constantes mudanças familiares. Também deve participar ativamente dessas mudanças, ou seja, promover mudanças em sua forma de atuação, a fim de que saiba lidar tanto com a família que tem tempo disponível para uma participação maior como com aquela cujos pais não têm tempo, pois é importante considerar que esta tem preocupações similares à daquela.

Estudos têm demonstrado os efeitos da importância da participação dos pais na escola para o desempenho escolar, mas a participação dos pais não deve ser vista como aquela que assegura o bom desempenho. O desenvolvimento escolar do aluno é um processo que se desenvolve na escola e com influência da família; não depende exclusivamente da família. A escola tem suas funções específicas que devem ser enfatizadas para que não se perpetue o discurso ideológico de que o desempenho depende da forma da família agir no contexto escolar do filho. Segundo Sankar-DeLeeuw (2002), incluem-se no processo de aprendizagem escolar os direitos e responsabilidades da escola bem como os de planejamento para as necessidades individuais exigidos pela escola, como benéficos para o rendimento escolar do aluno.

Autores como Allen e Fraser (2002) relatam que a presença dos pais na vida escolar é importante tanto para os alunos quanto para a escola. Por isso, é importante o vínculo da família com a escola, pois, segundo esses autores, é nas reuniões que são possibilitadas as condições de assistência aos pais, para que estes se conscientizem de sua importância para o desempenho escolar de seus filhos, conheçam sobre desenvolvimento e comportamentos de crianças e co-assumam responsabilidades em relação às atividades propostas pela escola. Para estes autores, os pais, quando percebem um ambiente de aprendizagem mais favorável, desenvolvem confiança em relação à escola, na medida em que verificam preocupação por parte escola com a educação de seus filhos.

Sheldon e Hopkins (2002) e Mapp (2002) descrevem a importância do envolvimento dos pais nas questões escolares e reconhecem que os pais são atores sociais e mantêm redes sociais que podem afetar o papel da educação dos filhos. Afirmam também que as concepções sociais e ou pedagógicas dos pais podem funcionar como um recurso proveitoso para as escolas e professores na educação de seus alunos. Portanto, quanto mais a escola se envolver, se preocupando e confiando nos pais e os reconhecendo como parceiros na educação escolar dos filhos, mais os pais se sentirão envolvidos e dispostos a colaborar. Quando se fala desse envolvimento, deve-se destacar que o aspecto freqüentemente ressaltado pela escola é o relacionado às situações de desempenho escolar do aluno, o qual é o responsável por muitos dos conflitos que se instalam na relação família-escola.

Sob o ponto de vista da participação dos pais, Burchinal, Peisner, Pianta e Howes (2002) afirmam que as crianças tendem a mostrar melhores habilidades acadêmicas se os pais tiverem maior envolvimento e maior grau de escolaridade. Descrevem, também, que quando os pais são mais participativos, as crianças evidenciam maior competência para a leitura, diminuindo os riscos de insucesso escolar nesse aspecto. Na questão da participação dos pais na vida escolar dos filhos, encontra-se também como fonte de conflitos nessa relação o nível de escolarização dos pais. Alguns pais pouco podem ajudar, pois se recolhem na ignorância, na inferioridade e demonstram carência de orientação, muitas vezes, por não serem instruídos para agir e orientar seus filhos. Contudo, na visão da escola, quando a vida escolar apresenta problemas, tanto os pais como os filhos são responsáveis pelo desempenho insatisfatório, na visão da escola (Peisner, Ellen, \& Yazejian, 2002).

Ainda sobre a participação dos pais e no universo escolar, Sígolo e Lollato (2001) enfocam os graus de aproximação entre a escola e a família. Revelam que a mãe, com maior fre- 
qüência, é quem acompanha as atividades escolares dos filhos e, a partir da realização de tarefas, em casa os pais podem perceber o desenvolvimento ou não de novos comportamentos. Um outro aspecto importante que esses autores concluem refere-se às condições de participação dos pais nas reuniões da escola, por terem verificado que há participação deles de acordo com a disponibilidade de seus horários, porém ocorre descontentamento, por parte deles, quanto aos assuntos que são tratados nessas reuniões.

Aspectos relacionados às ocupações dos pais também influenciam nas questões escolares. Muitas mães tentam participar e se envolver com a escola, mas poderiam se envolver mais se os locais onde trabalham concedessem a elas um período para ajudar os filhos, principalmente aqueles com dificuldade. Muitos estudos têm documentado a importância do envolvimento dos pais para o sucesso escolar dos alunos. Heymann e Alison (2000) assinalam que o envolvimento com a escola, na classe desfavorecida, é mais freqüente entre as mães do que entre os pais e que essas se envolvem, na medida em que conhecem o conteúdo escolar.

Em relação ao sucesso e ao insucesso escolar, o papel de educadora, em geral, tem sido desempenhado pela mãe, cabendo ao pai exercer o papel de provedor, mantenedor econômico da família. Parece comum no interior das relações familiares, que o pai tenda a apenas estimular o estudo e a mãe a se preocupar mais especificamente com o desenvolvimento da vida acadêmica do filho. O pai tende a procurar mais a escola para resolver problemas sociais, ou seja, quando o filho apresenta um comportamento indesejável e é repreendido pela professora, sendo comum registrar-se que o pai desempenha o papel de detentor do poder, conforme destacam Lewis e Forman (2002).

Para Goddard, Tschannen e Hoy (2001), o sucesso escolar é uma construção social que se constitui, freqüentemente, de crenças e concepções compartilhadas por pais e alunos. Dentre vários aspectos da dinâmica desse sucesso, faz-se necessária uma interação dos pais com o cotidiano escolar, incluindo a relação pais-professores, de modo a que ocorra um comprometimento da família com o sistema de ensino. Para esses autores, os pais de classe desfavorecida diante do insucesso escolar do filho, sentem-se desarmados e não questionam julgamentos, aceitam com resignação, afirmando, por exemplo: “ele não dá para o estudo, não leva jeito”, enquanto que os pais de classe mais favorecida tendem a referendar o julgamento da escola e a responsabilizar seus filhos. Para eles, é o aluno que não aprende, o que os leva a iniciar, então, a propiciar apoio a esse filho, dando mais atenção, auxiliando-o nas atividades escolares (preparando uma agenda, separando horários para estudo e para brincadeiras, lendo o livro da escola com ele, quando não por ele).

Na construção do desempenho escolar, a qualidade da escola é tão importante quanto a valorização do conhecimento escolar por parte dos pais, pois tanto uma quanto outra influenciam as condições de sucesso/insucesso escolar. Sheldon e Hopkins (2002) registram que a maioria das famílias acredita que a reprovação e o insucesso de seus filhos de- vem-se à própria deficiência da criança relacionada a causas orgânicas, mentais e motivacionais.

Como se pode observar pelo quadro dos trabalhos relatados, o panorama das pesquisas sobre a relação família-escola ainda se encontra em estágio bastante inicial. Contribuir para o seu desenvolvimento parece-nos fundamental para a sustentação de uma atuação do psicólogo que, na maioria das vezes, é chamado a mediar tal relação, seja pela escola, quando lhe atribui o papel de atender o aluno ou mesmo os familiares destes, seja pela família quando esta, se sentindo impotente na solução dos problemas e dificuldades do filho na escola, recorre a sua ajuda profissional.

Com a meta de contribuir para o desenvolvimento dessa temática, o objetivo do presente estudo foi o de investigar em que aspectos os discursos ou relatos dos pais de alunos com sucesso se diferenciam daqueles dos pais de alunos com insucesso escolar. Especificamente, identificar em que aspectos diferem as representações sobre a escola e o desempenho de pais de alunos bem-sucedidos e de pais cujos filhos estão vivenciando situação de insucesso escolar. Outra questão foi a de saber de que modo os pais constroem seus conhecimentos sobre a escola e o desempenho escolar dos filhos e como têm lidado com as concepções sobre sucesso e insucesso.

\section{Método}

O estudo foi realizado com pais de alunos de classe média baixa e baixa de uma escola pública estadual, residentes em um bairro de periferia de um município do interior do Estado de São Paulo. Estabeleceram-se os seguintes critérios: análise do histórico escolar do ano anterior dos alunos de $1^{\underline{a}}$ a $4^{\underline{a}}$ série do ensino fundamental; análise do histórico escolar desses alunos do primeiro bimestre do ano em curso e classificação dos alunos pelo professor de cada série correspondente. Optamos por estabelecer que fosse considerado como sucesso o aluno que, tanto no ano anterior quanto no primeiro bimestre do ano atual, apresentasse nota sete e acima de sete no histórico escolar do ano anterior e nas avaliações de classe do ano atual e classificado pela professora como um aluno de bom rendimento perante o desenvolvimento das tarefas. Consideramos como insucesso o aluno que apresentasse nota abaixo de sete no histórico escolar do ano anterior e no primeiro bimestre do ano atual e classificado pelo professor como de baixo rendimento ou nenhum rendimento perante o desenvolvimento das tarefas. A amostra foi composta por 32 pais (31 mães e 1 pai) de alunos matriculados no período da manhã e da tarde, sendo dezesseis pais de alunos com desempenho classificado como sucesso e dezesseis pais de alunos com insucesso escolar.

A pesquisa foi realizada durante o ano letivo de 2000 e teve início com observações no bairro onde a escola se localizava, as quais tiveram como finalidade conhecer os costumes e modos de vida dos moradores e contextualizar o estudo na sua realidade sociocultural. Em seguida, foram realizadas as entrevistas semi-estruturadas com os pais de alunos. 
Utilizou-se, também, a análise documental para contextualizar a história da escola no município e no bairro. Foram analisados arquivos históricos, sobre o município e o bairro, bem como documentos de registro da escola e os da Delegacia Regional de Ensino e Educação. A pesquisa caracterizou-se como um estudo qualitativo de natureza etnográfica, utilizando-se também a observação participante. Para a análise e interpretação dos dados obtidos recorreu-se à análise de conteúdo do tipo análise temática, tal como propõe Bardin (1977).

\section{Resultados}

Os resultados que serão apresentados a seguir consistem numa seleção do conjunto geral dos dados obtidos. Como nesse conjunto, também aqui, eles serão divididos em dois grupos: dos alunos com sucesso e dos alunos com insucesso. A análise de conteúdo revelou a possibilidade de levantar diversas categorias: a escola e o contexto; a família e o seu contexto; a escola na percepção dos pais; o desempenho escolar na percepção dos pais; a presença dos pais ${ }^{1}$ no dia-adia escolar dos filhos; os professores do filho sob o olhar da família e o significado do estudo sob o olhar da família. Neste artigo, apresentamos os resultados classificados na categoria sobre o desempenho escolar na percepção dos pais.

\section{O desempenho escolar para a família de filhos com sucesso escolar}

Alguns dos aspectos que desvelamos em nossos dados, através dos relatos dos pais, levaram-nos a considerar que as práticas educativas incluem distintos aspectos, quando focalizadas as que ocorrem na escola. Entre esses se destacam: a relação entre os pais e os filhos, as atitudes dos pais em relação à escola, o rendimento escolar e a preocupação e interesse dos pais em relação ao desempenho escolar de seus filhos. Os alunos que recebem apoio apresentam mais habilidades nas tarefas, desenvolvem uma auto-estima positiva em relação à escola e ajustam-se melhor psicologicamente. Estes são alguns dos aspectos que desvelamos em nossos dados, através dos relatos dos pais. Embora, em geral, os pais compreendam o desempenho escolar dos filhos, alguns se sentem incapazes de ajudá-los por diversas razões, até mesmo por falta de orientação por parte da escola. O empenho para entender e, de certa forma, ajudar o filho nas dificuldades que está experimentando, tem sido uma preocupação constante no dia-a-dia dessas famílias, tanto daquelas com filho com sucesso, como das que lidam com insucesso escolar de seu filho.

Registramos que os pais podem até ser capazes de resolver alguns problemas, mas não estão totalmente seguros de sua efetiva participação. Quando conseguem entender como o desempenho ocorre na vida escolar dos filhos, visto sob as próprias perspectivas, de alguma forma revivem e apropriamse de suas experiências as quais, muitas das vezes, não coincidem com as que emergem da perspectiva da escola.

\section{História escolar}

Os relatos obtidos através das entrevistas com os pais de alunos com sucesso escolar, mostraram que os filhos apre- sentam uma história escolar boa, ou seja, afirmam que os filhos, desde o maternal ou da pré-escola, constroem uma percepção positiva da escola e das atividades escolares. Observamos, na grande maioria, que os alunos com sucesso escolar tiveram uma trajetória de bom rendimento desde o início da vida escolar, e de certa forma, o sucesso escolar inicial pode ter contribuído de forma positiva para a realização das práticas escolares e determinado uma base importante para a continuidade da vida escolar.

Ao refletirem sobre histórias escolares de seus filhos com sucesso, os pais passam a impressão de que o mesmo depende do modo que o aluno inicia sua trajetória escolar. Incluem nessa trajetória, a postura da família em relação à valorização da escola. Parecem acreditar que quando seus filhos possuem uma boa imagem da escola, apresentam uma boa história escolar. O sucesso escolar para essas mães supõe uma série de condições, entre elas, um bom comportamento inicial, ou seja, ir bem à escola desde o começo, e as relativas às responsabilidades que devem ser assumidas tanto pela família quanto pela escola. Observamos, ainda, que a partir do início da educação escolar, a família pode assumir entre suas responsabilidades as de não pressionar seus filhos, atribuindo um significado positivo para a escola e o aprender.

\section{Percepção sobre o desempenho do filho}

Entre as razões sobre o desempenho escolar do filho com sucesso, a maioria das mães revela uma valorização quanto à organização, isto é, para elas os alunos organizados têm um bom desempenho. Os pais constroem sua percepção positiva sobre o desempenho escolar, a partir de diferentes indícios sobre a vida escolar: realização das atividades escolares, cuidado com o material escolar e comportamento em sala de aula. Parece que predomina a idéia de que ordem e capricho com os materiais e com as atividades escolares é sinal de bom desempenho. Os pais parecem possuir uma percepção positiva sobre o desempenho escolar do filho associando a ele a responsabilidade com tarefas e atividades de sala de aula. A crença de que aluno bom faz sempre as tarefas é sinal de organização.

\section{O papel dos professores no rendimento escolar do filho}

Também observamos que quando os pais relatam o desempenho escolar como satisfatório, insinuam que o percebem como sendo fruto da ação dos professores. Essa noção parece-nos determinada porque os pais esperam uma avaliação, mesmo que implícita, da professora sobre o desempenho escolar do filho. Os pais parecem ver uma relação entre o sucesso escolar e a relação professor-aluno. A crença de que o bom desempenho depende do professor faz-se muito presente.

A maioria das mães inclui o vínculo positivo do professor com o aluno ao justificarem o sucesso escolar dos filhos. O sucesso escolar do aluno tem, para as mães, muita razão de ser, devido aos laços criados com a professora em sala de aula. Isto nos leva a pensar que para essas mães, a auto- 
estima positiva do aluno pode ser desenvolvida também pelo professor e é um fator que auxilia no sucesso escolar.

\section{Auxílio dos pais nas tarefas escolares}

Podemos perceber que a importância do auxílio dos pais nas tarefas escolares é mencionada por todos os pais de aluno com sucesso escolar. Revelam uma preocupação diante das responsabilidades acadêmicas, bem como realizam o acompanhamento do processo de ensino e aprendizagem. Observamos que as mães são mais presentes no auxílio às atividades, apresentam um cuidado maior, dão mais atenção e mostram-se mais presentes na realização das tarefas de casa. Elas acreditam que os filhos precisam desse auxílio e principalmente da atenção delas. As mães relatam que o auxílio dos pais nas atividades escolares pode despertar um interesse maior do filho pelo estudo e também manter um vínculo positivo com o desempenho escolar.

Outro ponto importante dos relatos é a relação entre o auxílio dos pais nas atividades escolares e a finalidade do estudo, ou seja, os pais parecem preocupados em eliminar a ociosidade dos filhos, estimulando o estudo, lembrando a importância das atividades escolares. Observamos que os pais percebem o auxílio às atividades escolares como forma também de despertar a responsabilidade no filho para com o futuro da vida escolar.

O auxílio às tarefas escolares faz parte do cotidiano familiar. Poderíamos dizer que, mesmo as mães que trabalham fora, têm consciência de que os filhos levam para casa atividades que precisam ser desenvolvidas. Diante disso, observamos que para algumas esse auxílio vem em forma de diálogo, ou seja, na impossibilidade de ajudar o filho, elas os orientam a prestarem atenção na aula e a tirarem as dúvidas que aparecerem. Observamos que algumas mães dão ênfase à orientação de como não ter problemas com a tarefa de casa:

Eu acho que é só conversa mesmo. Em casa e ajuda. A tarefa ajuda bastante, estou sempre presente em casa. Mas eu converso muito pra prestar bastante atenção na aula, porque eu num tenho muito estudo, então, quanto mais ele prestar atenção, mais facilidade ele vai ter para fazer a tarefa sozinho. Eu num tenho condições assim de ajudar muito, então, eu converso muito e verifico, se está bem feitinho, se ele está copiando certinho da cartilha, sabe? Converso bastante mesmo. (Mãe 17)

Muitas mães não conseguem ajudar nas tarefas porque não entendem o que é para fazer. Os métodos de ensino modificam-se muito e isto acaba sendo um fator que leva as mães a terem dificuldades em acompanhar os filhos em suas tarefas domiciliares. Os relatos revelam que elas sentem vontade de ajudar, mas se vêem impossibilitadas por não entenderem as tarefas. Quando se propõem a ajudar, os próprios filhos não querem porque temem que as mães não ensinem tal qual a professora ensinou, ou muitas vezes, mandou. Isto parece indicar a necessidade das tarefas serem mais bem explicadas para os alunos, a fim de poderem realizá-las em casa sem problemas.

\section{Razões ou responsabilidades para o sucesso escolar}

Quanto às razões ou responsabilidades a que os pais recorrem para explicarem o sucesso escolar, parecem surgir duas perspectivas: a primeira é observada numa experiência relatada que envolve a questão das razões para o sucesso escolar primeiramente na manifestação da crença de que Deus é o responsável pelo sucesso do filho, ao mesmo tempo em que a mãe também responsabiliza a própria criança pelo bom desempenho, acrescentando ainda o estímulo dos pais. Neste sentido, parece haver uma idéia de que, se a criança tiver interesse, força de vontade e estímulo dos pais, podem até ocorrer situações propícias para desencadear um insucesso, mas, mesmo assim, a criança consegue vencer os problemas e atingir um bom rendimento, com a ajuda de Deus. O característico aqui é que nenhuma referência é feita aos professores ou questões intra-escolares. Diz a mãe:

\begin{abstract}
Ah! Eu tenho que agradecer a Deus, eu procuro ensinar o que eu posso, mas só que, o demais, eu acho que tudo vem de Deus, porque num é possível, o pobrema que eu tive na gravideis, e ela sê assim o que ela é hoje na escola. Nossa! Então, eu acho que primeiro ela é assim, muito boa aluna por Deus e depois por ela mesmo, porque, o que ela passou dentro de mim, era pra sê uma aluna muito ruim, ela tinha tudo pra sê péssima na escola, e ela com interesse, aproveitou, num se deixou abalar, com os pobrema da gravideis. Então, eu penso que primeiro é porque Deus ajuda muito ela e depois ela que soube aproveitar tudo de bom que a escola tem dado pra ela. (Mãe 1)
\end{abstract}

A segunda perspectiva é revelada na maioria dos relatos. Nela observamos que, para os pais, o fato de a criança apresentar um sucesso escolar está relacionado, em primeiro lugar, à própria disposição da criança para aprender; depois, ao estímulo e apoio dos pais. Por último, os pais relacionam o sucesso escolar ao trabalho do professor, ou seja, acreditam que cada um desses elementos tem o seu papel a ser desenvolvido e a harmonia desses papéis resulta no sucesso escolar:

Eu penso que ele é bom aluno, é porque a gente: eu e o pai dele mostra, conversa, incentiva. (...). Então eu penso que um pouco vem da gente que dá apoio, outra coisa é que ele vê que vai bem, então, ele se estimula, e a outra coisa também vem da professora que tem paciência com ele, explica direitinho, tem vontade de ensinar tem muita paciência com ele. (Mãe 3)

Outro dado importante quanto à razão atribuída para explicar o desempenho surge em relatos das mães que têm a crença de que o filho vai bem, porque é parecido com os pais. Parecem acreditar que o bom desempenho é hereditário, tanto pode parecer com o desempenho da mãe quanto do pai. Os relatos referem-se a uma suposta justificativa hereditária, anulando a possibilidade de o desempenho ser único, singular para cada criança.

É interessante notar em um relato que a mãe parece querer justificar o sucesso escolar como algo hereditário, mas ao 
mesmo tempo, revela que isso não é possível porque ambos os pais não possuem uma história escolar de sucesso. Dentro dessa experiência, é possível pensar na crença que os pais têm quanto aos fatores hereditários da inteligência. Para eles, o fato de o filho ir bem ou não, deixa-os em dúvida quando percebem que vão bem, mas não têm nada a ver com os pais, mesmo porque esses nunca tiveram oportunidade de ir muito longe com o estudo. Diz a mãe:

Ah, eu num sei devido a que ele é bom assim na escola. O pai dele num foi nunca de ir pra escola, ficava enforcando aula e não estudava e era péssimo aluno. Eu sempre, eu falo verdade: Nunca gostei de estudar, não. Ou, sei lá, né? A gente, eu, num sei te explicá, né? Eu num sei pra quem ele puxou. (Mãe 21)

\section{O desempenho escolar para a família de alunos com insucesso escolar}

Neste conjunto de relatos observamos diferentes perspectivas da percepção dos pais sobre o desempenho malsucedido do filho na escola. Com relação à história escolar, a trajetória é marcada por situações insatisfatórias. O filho já inicia o percurso da vida escolar apresentando dificuldades no rendimento.

\section{História escolar}

$\mathrm{Na}$ maioria dos relatos, estão presentes as queixas dos pais que vão desde problemas com a adaptação escolar até o fato de os filhos não conseguirem aprender. Apesar de se declararem interessados em acompanharem a vida escolar de seus filhos, os pais reconhecem que este fato não assegura que seus filhos possam apresentar um bom rendimento.

Outro dado muito significativo sobre a história escolar é revelado em um relato em que o desempenho aparece interligado a outras experiências vivenciadas pelo filho. Para essa mãe, o insucesso escolar está também ligado às conseqüências do divórcio. Mostra, principalmente as conseqüências negativas de seu ato de educar. Na sua opinião, o filho sofreu vários conflitos gerados pelo seu comportamento inconseqüente e egoísta, isto é, a mãe revela que em algumas situações, pensou mais nela do que nos filhos. A história escolar é apontada aqui como uma trajetória repleta de sofrimentos e séries inacabadas, ou seja, nunca completou uma série normal.

Ainda que não avaliem negativamente a história escolar dos filhos, algumas mães têm consciência de que alguma coisa aconteceu de errado na aprendizagem do filho, mas não sabem dizer o que é. Os relatos revelam que até uma dificuldade de aprendizagem pode ter sido mascarada como problema de ordem comportamental.

\section{Percepção sobre o desempenho escolar do filho}

O desempenho escolar malsucedido, sobretudo aquele relativo à dificuldade de aprendizagem, é uma constante na maioria dos relatos destes pais. Nesse aspecto, o insucesso escolar inicial e o sucesso mediano constituem situações de queixas e desabafos dos pais, que tentam elucidá-lo com vários questionamentos. Além disso, parece que os pais de- monstram conhecer o desempenho escolar, mas não o compreendem e nem conseguem defini-lo.

Compreender a dificuldade de aprendizagem do filho para as mães é algo difícil. Mas o interessante é que alguns relatos revelam que elas percebem a dificuldade através da comparação com o desempenho de outro filho. Isto significa que as mães não sabem a causa da dificuldade, porém têm consciência de que ela existe, quando comparam com o rendimento escolar dos irmãos. A situação parece ser muito complexa para elas, quando relatam que uns têm problemas e outros não.

Observamos um relato interessante no qual a falta de orientação sobre a dificuldade de aprendizagem da filha é tão grande que a mãe se dispõe a concordar com a professora em levá-la para uma escola especializada, a Associação de Pais e Amigos dos Excepcionais (APAE). Mais que a anuência da mãe com tal atitude da professora, surpreende a falta de conhecimento específico sobre dificuldades de aprendizagem, possivelmente devido a falhas no curso de formação de professor, ao tomar a decisão de encaminhar crianças que apresentam dificuldades, em lugar de fazerem um plano de ensino diferenciado; especialmente no momento atual, em que a luta dos educadores é pela inclusão. Possivelmente por desconhecimento, os pais acabam concordando: sem saber o que fazer e com a preocupação de ver o filho atingir um bom rendimento, concordam com a atitude da professora, sem nenhuma objeção:
A professora (Nome da professora) é conversô comigo pra encaminhar ela pra ir pra APAE, né? Ela disse que aqui num tem como ela ensinar minha menina, ela tem que acompanhar os outros que sabem mais. Falou também que lá, tem de todos tipo de professor, tem um médico, né? Tem psicólogo, né? E aqui já num tinha. Ela veio e chamô eu pra vê se eu aceitava. Ah, eu aceitei. Porque, tudo que eles faz de esforço pra ela eu acho que é melhor, né? É o que eu quero que ela aprende né? Se aqui num tem jeito, então, vamos levar lá pra ver se resolve, né? (Mãe 30)

\section{O papel do professor no rendimento escolar do filho}

Verificamos que as impressões dos pais frente ao desempenho malsucedido também revelam um descontentamento em relação à professora. Observamos que os pais fazem uma idéia de que a professora deveria se esforçar mais na ajuda à criança, mas, para os pais as professoras também não sabem lidar com as dificuldades dos alunos. Observamos também, nessa perspectiva, a "medicalização" do insucesso como uma das possíveis explicações para as mães:

Sei lá, a professora fala que ele é distraído, num tem vontade, escreve quatro vez errado, depois na quinta escreve certo, aí torna esquecer e fazer errado de novo. Mais eu acho que ele num sabe mesmo. Agora na lição eu num falo nada, é um fracasso mesmo. Oh, mais que nós falamos, o pai dele ainda fica bravo, raia com ele, num adianta na classe ele num lê, ele num faz. (Mãe 6) 
No relato a seguir, a mãe descreve a posição da professora frente ao desempenho, além disso, revela que a professora justifica o baixo rendimento a partir de possíveis fatores traumáticos ocorridos no meio ambiente familiar:

A professora fala que, às vezes, tem hora que ela aprende, mais tem hora que o sentido dela tá longe, num aprende nada, minha filha fala que é a professora que num ensina. (...) Agora a professora fala que pode sê por causa do drauma que ela tem. $\mathrm{O}$ pai dela foi preso e ela tava lá na hora, a professora fala que, às vezes, é isso né, ela tá draumatizada. (Mãe 14)

\section{Auxílio dos pais nas tarefas escolares}

Estes relatos foram especialmente consideráveis, pois reflexões sobre o insucesso escolar dentro de um contexto específico vieram à baila e deixaram claro que as mães esperam orientações adequadas dos professores sobre como ajudar os filhos a vencerem o insucesso escolar. Portanto os pais de alunos malsucedidos não estão alheios aos problemas do filho; muitas vezes o que lhes falta é uma orientação adequada. Confirmando isso, eis o que diz esta mãe:

Ele é muito preguiçoso, se num pegar no pé dele, num faz, porque ele é muito distraído, a professora fala: a senhora tem que forçar ele, tem que forçá ele. Mais forçar de que jeito eu pego nu pé dele, mais num adianta, eu num sei que jeito forçar ele. Então, eu acho que a professora devia exigi mais dele, passar continha, tabuada, fazer leitura, porque ele está péssimo, eu acho se a professora também num ajudar ele, e me falar direitinho o que tem que fazer, ele vai pra quarta série sem saber ler, sem saber nada mesmo, eu acho que a professora também num sabe o que eu posso fazer. (Mãe 6)

Observamos que a presença dos pais de alunos com insucesso escolar nas tarefas é bastante ativa, mas permeada de dificuldades, ou seja, os pais tentam auxiliar, buscam estratégias, mas não conseguem atingir os objetivos, muitas vezes, por falta de entendimento pedagógico ou mesmo orientações específicas. Além disso, auxiliam e acompanham as tarefas com base no nível escolar que têm, o que na maioria, é baixo ou até mesmo ausente, o que torna difícil o auxílio. Dentro dessa perspectiva, os pais prontificam-se a auxiliar e participar das explicações das tarefas utilizando recursos tradicionais da própria vida escolar trazidos pela memória, mas parece evidente a dificuldade deles diante dos problemas de aprendizagem.

Enquanto algumas mães sentem-se perdidas diante das dificuldades dos filhos, outras realizam várias tentativas, esperando conseguir atingir os objetivos do desempenho bemsucedido, persistindo na questão do acompanhamento do filho, em que supervisionam não só o andamento e o desempenho acadêmico, como também utilizam meios para resgatar o bom desempenho e sugerem ajuda da escola.

Há também a consciência do compromisso da mãe com o material escolar como forma de auxiliar o filho a superar o mau desempenho. Os relatos revelam esse compromisso em dois sentidos: o primeiro é o de auxiliar nas tarefas, algumas mães compreendem a vigilância dos materiais como um método de ajudar o filho a se interessar pelas atividades escolares; o segundo é o de gerar disciplina, responsabilidade e cuidado. Isto significa que para algumas mães, os filhos que apresentam insucesso escolar não têm cuidado com o próprio material. Portanto, justificam essa atenção como forma de auxiliarem os filhos a superarem o insucesso:

As tarefas eu quase num faço porque é feito no Caminhando. Mas de vez em quando, eu olho a bolsa dele, mas a bolsa dele, dá até tristeza você vê, tem cara de bolsa de gente que num aprende mesmo. Os caderno cheio de orelha (. . .) A professora. falou: “(Nome da mãe), só falta ele comer o lápis“. Eu num sei, eu num sei, por que esse tipo de pobrema. Então, eu estou em cima pra vê se ele toma gosto pelas tarefas. (Mãe 18)

O auxílio às tarefas, para uma mãe, é tão significativo que pode desempenhar uma função salvadora no insucesso do filho. Através das tentativas muitas vezes fracassadas, a mãe tenta, incansavelmente, lutar contra o insucesso. A mãe experimenta várias atitudes e, em determinadas situações impõe regras, dedicando uma atenção exaustiva ao filho para mudar o comportamento dele na aprendizagem.

Outro relato revela-nos que, pelo fato de não saber ler e escrever, a mãe recorre aos outros filhos para ajudar o que tem dificuldade de aprender. Isto mostra que o fato de a mãe ser analfabeta, não significa que o filho fique sem auxílio nas atividades escolares. Esse relato mostra que o interesse da mãe para que o filho consiga sucesso, leva-a a ter outras iniciativas de ajuda, por exemplo, buscar a cooperação dos irmãos:

É os minino sempre ajuda, que eu num sei, né? Num sei a leitura, num sei escrever. Mas sempre os irmão dela em casa eles exprica prá ela como é que é, como é que num é, né ? Na hora dela fazê... Se ela faz dum jeito, eles falam: "Cê tem que fazê desse jeito”. Mais eles estando em cima dela, ela, ali ela faz direitinho. (Uma se, qualquer um estando fora?) já faz tudo errado. (Mãe 32)

\section{Razões ou responsabilidades para o insucesso escolar}

As concepções dos pais sobre a atribuição da responsabilidade do desempenho malsucedido são construídas a partir de críticas realistas ao processo de ensino e aprendizagem, contrapondo com a culpa que atribuem a si próprio. O trabalho da escola é considerado insatisfatório pelas mães devido à precariedade de determinadas condições da escola pública tais como: escola em má situação, professores despreparados e modo de ensinar ineficaz. As mães revelam ainda que os professores justificam o desempenho malsucedido apontando as causas nos lares desfeitos, como aponta este relato:

Ah! as professora me fala que a situação do pai largá ele deu pobrema nele, que isso daí tem tudo a ver com o pobrema dele, tem tudo a ver. Que isso daí tá prejudicando o menino. Mais tantos pais que largam o filho e nem por isso os filhos são burro, né? Pra mim é os professores que num tão conseguindo fazer ele aprender a ler e a escrever, porque, num é porque é 
escola do governo que ele num vai aprender a ler e a escrever, ele vai ficar uma criança burra, porque eu num tenho condições de pagar uma escola particular, que lá, das vezes, elas iam se preocupar mais, tem menos aluno na classe , porque isso ajuda né? E também, porque eu acho que isso daí de ensiná é um dever da escola, deles aqui a puxá essa criança ou mandá pa algum lugar, ou sei lá fazer o quê. O menino num sabe ler e nem escrever, eu acho que aqui é uma falta deles, eu acho que isso é dever da escola, a fazer as criança aprender a ler e a escrever. (Mãe 4)

Ou neste, que revela uma crítica bastante realista sobre a mudança de professores na escola pública:

Eu acho que ele vai mal porque, porque [silêncio] não sei se foi porque mudou muito de professor, ele teve três professora, onde já si viu isso? Veio a primeira saiu, depois entrou a segunda, aí foi substituta pra segunda professora, aí veio a terceira no fim do ano já, quase em novembro. Então, isso mexeu muito com a cabeça dele. Cada uma ensina de um modo, a outra vai ensina de outro né? Mas eu acho que isso dificulta um pouco a criança nu estudo né? Começa a embaraiá, entende? Eu acho que pode até dá um drauma e depois que fica draumatizado, aí é muito difícil ir pra frente. (Mãe 6)

Observamos que alguns relatos revelam que as mães acreditam na possibilidade de que teriam que terem sido mais rígidas, ter colocado mais limites e, além disso, ter mantido o controle disciplinar. Relatam que o excesso de zelo e o mimo estragam os filhos. O modo como os educaram parece ser avaliado pelas mães de forma negativa, em função da ausência da autoridade perante os filhos:

Eu acho que um pouco também [silêncio] acho que foi eu que errei, porque eu dei muito mimo, então, tudo que ele quer eu pego e dou, agora eu estou repreendendo né? Mais eu acho que está um pouco tarde prá repreender, mais vamos tentar né? Não custa nada, então, um pouco esse sossego, essa falta de interesse, um pouco vem da escola, mais um pouco vem de mim. Porque o meu marido fala: "você mima muito esse moleque, você num força ele”. Então, isso ajudou ele ser sossegado desse jeito. (Mãe 10)

Uma outra concepção sobre as razões do insucesso escolar que foi revelada, diz respeito a uma explicação mais ideológica: muitas mães tentam responsabilizar o filho pelo insucesso, protegendo de maneira inconsciente, a escola e a família:

Ah! às vezes, eu acho que é um pouco de preguiça dela vir na escola [silêncio] eu acho que deve ser dela mesmo num querer aprender. Ela mesmo que num tá disposta [silêncio]. Então, eu acho que num é pobrema da escola não, ou da professora dela; é dela memo. É a falta de vontade, né? Falta de vontade dela. (Mãe 8)

Observamos num relato que a mãe revela o cuidado que deveria ter tido desde o início com vida escolar do filho. Parece que o modo de agir a respeito da vida escolar e o processo de aprendizagem concretizam a responsabilidade sobre o de- sempenho acadêmico para essa mãe. Ela também usa de uma analogia ao referir-se à vida escolar ideal para uma criança:

Eu penso que foi, as mau série terminada no começo, tá entendendo? Eu devia ter tomado mais cuidado. Porque acho que é igual uma planta: se você planta uma planta, depois se você num molha ela. Ela num vai viver. E eu acho que o (Nome do filho) tinha que ser lá debaixo, né? No maternal, tudo direitinho, terminá o ano, sabe? Bonitinho, pra hoje está bem? Hoje, hoje num sei o que eu faço. Hoje eu num sei o que eu faço, o (Nome do filho) parece uma planta que minguô, entendeu? Nasceu, mas num cresceu. (Mãe 18)

\section{Síntese comparativa dos dois grupos de família}

Os nossos dados mostraram que o desempenho escolar parece ser especialmente importante para as famílias as quais apresentam várias percepções, que, na realidade, são mais do que crenças ou idéias, e podem ter se tornado tão fortes que se transformaram em saberes compartilhados na estrutura familiar. Faz uma grande diferença o modo com que a família percebe, por exemplo, o sucesso escolar; se essa família vê o desempenho do filho como sucesso, diferente de outra que o vê como insucesso. Podemos observar as diferentes percepções dos pais acerca do desempenho escolar na Tabela 1.

A partir da idéia de que a sociedade modela os modos de pensar, sentir e agir, o conceito do papel do desempenho escolar para a família pode ser encarado como uma resultante cultural, ou seja, dos modos de pensar experienciado nos contextos familiares. Mais especificamente, a presente análise mostrou o estabelecimento de uma relação de comunicação entre os papéis dos pais, do professor e do aluno dentro da relação família-escola. É possível pensar que essas relações podem ser uma pista para a compreensão das condições que podem determinar as representações e crenças sobre o sucesso escolar.

Nossos dados revelaram que tanto as famílias de alunos com sucesso como as com insucesso dedicam uma grande atenção à vida escolar dos filhos. Os pais de alunos com sucesso atribuem, na história de seus filhos, um significado muito positivo para a escola e o aprender, já os pais de alunos com insucesso, revelam uma história permeada de dificuldades. Interessam-se pela vida escolar dos filhos, conhecem sua história de insucesso, mas parece que apresentam muitas dúvidas em relação à compreensão do significado do desempenho malsucedido. Também possuem várias crenças, nem sempre fundamentadas, sobre a história escolar.

Acreditamos que o desempenho escolar pode ser uma das questões em relação à qual pais e filhos enfrentam grandes dificuldades. Os pais por quererem que os seus filhos sejam avaliados pela sociedade como um indivíduo capaz, e os filhos por quererem satisfazer as expectativas dos pais. Em outras palavras, parece existir certa consistência em relação à necessidade de sucesso escolar no interior da família que pode persistir ao longo da vida dos filhos. Os relatos dos pais revelam o que o sucesso escolar deriva de situações como responsabilidades para com as tarefas, cuidado com o material escolar, disciplina em sala de aula entre outros. Os 
Tabela 1

O desempenho escolar na percepção dos pais

\begin{tabular}{|c|c|}
\hline Família de aluno com sucesso & Família de aluno com insucesso \\
\hline $\begin{array}{l}\text { Categoria 1: história escolar } \\
\text { História escolar boa: desde o início os filhos apresentam uma tra- } \\
\text { jetória de sucesso escolar; } \\
\text { Os pais passam a impressão de que o sucesso escolar inicial consti- } \\
\text { tui uma base para a continuidade da vida escolar; } \\
\text { Valorizam a conduta pedagógica da primeira professora; } \\
\text { Transmitem um significado positivo sobre a escola e o aprender. }\end{array}$ & $\begin{array}{l}\text { História escolar ruim: desde o início os filhos apresentam uma } \\
\text { trajetória de insucesso; } \\
\text { Problemas com adaptação escolar e dificuldades de aprendizagem; } \\
\text { Somente o interesse dos pais na vida escolar do filho não garante o } \\
\text { bom desempenho; } \\
\text { Crença de que o divórcio dos pais contribui para uma história } \\
\text { escolar de insucesso. }\end{array}$ \\
\hline $\begin{array}{l}\text { Categoria 2: percepção sobre desempenho escolar do filho } \\
\text { Sinal de bom desempenho: revelam preocupação com a organiza- } \\
\text { ção por parte dos filhos: realização das atividades escolares; cuida- } \\
\text { do com o material escolar; bom comportamento em sala de aula; } \\
\text { Crença: bom aluno é aquele que sempre faz as atividades em sala de } \\
\text { aula e cumpre as tarefas de casa. }\end{array}$ & $\begin{array}{l}\text { Conhecem o desempenho ruim do filho, mas não compreendem e } \\
\text { nem sabem defini-lo; } \\
\text { Visão realista da dificuldade de aprendizagem do filho; } \\
\text { Possuem também filhos com sucesso escolar; } \\
\text { Crença: um aluno com dificuldade precisa de escola especial (APAE). }\end{array}$ \\
\hline $\begin{array}{l}\text { Categoria 3: papel dos professsores no rendimento escolar } \\
\text { O professor tem um papel importante; } \\
\text { O sucesso do filho depende da boa relação professor-aluno; } \\
\text { Crença: o sucesso do aluno depende também do professor; } \\
\text { Auto-estima positiva do aluno desenvolvida pelo professor auxilia } \\
\text { no sucesso escolar. }\end{array}$ & $\begin{array}{l}\text { Descontentamento com a professora; } \\
\text { Os professores não desempenham o papel real: não sabem lidar } \\
\text { com as dificuldades dos alunos; } \\
\text { Crença: os professores não realizam esforços para ajudar o aluno } \\
\text { com insucesso. }\end{array}$ \\
\hline $\begin{array}{l}\text { Categoria 4: auxílio dos pais nas tarefas escolares } \\
\text { Todos os pais entrevistados relatam que auxiliam na tarefa escolar; } \\
\text { As mães são mais presentes no auxílio às tarefas, dão mais atenção, } \\
\text { apresentam um cuidado maior; } \\
\text { Estimulam o estudo e despertam responsabilidades; } \\
\text { Mães que trabalham e possuem pouco estudo, orientam os filhos para } \\
\text { que prestem atenção às aulas e tirem suas dúvidas com a professora; } \\
\text { Criticam a constante mudança de metodologia, o que indica a difi- } \\
\text { culdade de auxílio. }\end{array}$ & $\begin{array}{l}\text { Não recebem orientação adequada para auxiliarem os filhos; } \\
\text { Buscam estratégias de auxílio, mas não conseguem atingir os objetivos; } \\
\text { Faltam-lhes entendimento pedagógico e orientações específicas; } \\
\text { Presença ativa nas tarefas; } \\
\text { As mães supervisionam e assessoram o andamento escolar e o } \\
\text { desempenho acadêmico; } \\
\text { Supervisionam material escolar e estimulam a responsabilidade; } \\
\text { Luta contra o insucesso: mães analfabetas pedem ajuda aos filhos } \\
\text { com sucesso escolar. }\end{array}$ \\
\hline
\end{tabular}

Categoria 5: razões ou responsabilidades para o sucesso ou insucesso escolar

Deus é o responsável: depende do interesse da criança, da família e do professor.

Precariedade da Escola Pública; culpam a escola, os professores e o modo de ensinar; mudança de professores; excesso de mimo. pais de alunos com insucesso têm plena consciência das dificuldades deles, mas não conseguem compreender o desempenho e muito menos definir suas razões. Isso, talvez, porque não conseguem compreender por que possuem filhos que apresentam insucesso e filhos que apresentam sucesso.

Tanto os pais de alunos com sucesso quanto com insucesso acreditam que as ações da professora influenciam no rendimento escolar. Os pais de alunos com sucesso relatam que o bom desempenho depende também da professora, enquanto os de alunos com insucesso revelam um descontentamento com ela, julgando que o desempenho malsucedido pode ser responsabilidade da professora. Contudo, observamos em nossos dados que as famílias, ou melhor, as mães, principalmente aquelas cujos filhos estão inseridos nos casos de insucesso, fazem-se muito presentes, assessorando os filhos nas tarefas, na organização do material entre outros, mas revelam que precisam ser mais bem orientadas.

Mães que trabalham fora ou possuem baixa ou nenhuma escolaridade, revelam conhecimento e apoio ao filho, mesmo que a seu modo. Não verificamos descaso por parte delas nem desconhecimento das dificuldades dos filhos. Os pais de filhos com sucesso escolar revelam que o êxito ou o bom desempenho é responsabilidade da criança, da família e do professor, enquanto que os pais de alunos com insucesso direcionam a responsabilidade à escola e aos professores, mas alguns relatos revelam também que o excesso de mimo e a falta de limites colaboram para o insucesso.

\section{Considerações finais}

A análise dos relatos que os pais fazem sobre a educação escolar encaminha para várias reflexões tais como: uma profunda revisão da função social da escola; uma redefinição de seus objetivos para os alunos atuais; modificação dos seus pontos de vista sobre a família de alunos com insucesso; organização de um currículo que consiga atingir o aluno com dificuldade de aprendizagem; desenvolvimento de métodos de ensino e aprendizagem adequados a alunos com sucesso e insucesso. Os resultados obtidos evidenciam também que a percepção positiva ou negativa da escola pode ser um fator 
determinante nas relações que seus filhos estabelecem com a escola. Mesmo nestes casos, é possível identificar a relevância do interesse e o empenho dos pais no desenvolvimento escolar dos seus filhos.

Com o envolvimento dos pais no cotidiano escolar dos filhos, as atividades planejadas e executadas pela escola podem favorecer o sucesso no processo de aprendizagem dos filhos. As mudanças nas visões da família acerca da escola, se de fato estiverem ocorrendo, podem se tornar importantes para o sucesso escolar dos filhos, desde que a escola se conscientize mais sobre a verdadeira importância dos pais nesse processo, e conjuntamente ajustarem os seus ritmos de atuação, negociem e recriem os significados de cada um dos envolvidos sobre a educação escolar.

Poderíamos suspeitar que o tipo de auxílio que as famílias oferecem a seus filhos está relacionado à forma com que os pais foram educados e às dificuldades recorrentes da baixa escolaridade que estes possuem. Em geral, os pais admitem que participam, auxiliam e assessoram, mas sentem falta de uma melhor orientação, o que significa que a família está disposta a participar e cooperar com seu filho em seu insucesso. Todavia, o fato de a diferença no nível de escolaridade não se mostrar significativa entre os pais dos alunos com sucesso e com insucesso, obriga-nos a pensar que as dificuldades dos pais destes alunos possam ter origens em outros fatores.

A percepção negativa da escola e a modalidade de participação de alguns pais devem-se, talvez, à falta de esforço da estrutura educacional atual, para entender que a história escolar, tanto dos pais quanto dos filhos, pode, enfim, propiciar experiências cumulativas de frustração, capazes de impedir que a família reconheça o valor da escola e de sua participação na vida escolar de seus filhos.

Acreditamos que o presente relato e análises possam contribuir para a temática das relações da família com a escola, ainda pouco explorada, e constituir-se em um passo para que a escola proponha programas de orientação capazes de identificar o tipo de dificuldade específica dos pais para auxiliarem os filhos.

\section{Referências}

Allen, D., \& Fraser, B. J. (2002). Parent and student perceptions of the classroom learning environment and its influence on student outcomes [Resumo]. In American Educational Research Association (Org.), Annual Meeting of the American Educational Research Association (p. 298). New Orleans: Autor.

Bardin L. (1977). Análise de conteúdo. Porto: Edições 70.

Burchinal, M., Peisner, F., Pianta, R., \& Howes, C. (2002). Development of academic skills from preschool through second grade: family and classroom predictors of developmental trajectories. Journal of School Psychology, 40(5), 415-436.

Carvalho, M. E. P. De. (2000). Relações entre família e escola e suas implicações de gênero. Cadernos de Pesquisa, 110,144-155.

Collett, B. R., Gimpel G. A., Greenson, J. N., \& Gunderson, T. L. (2002). Assessment of discipline styles among parents of preschool through school-age children. Journal of Psychopathology and Behavioral Assessment, 23(3), 163-170.

Goddard, R., Tschannen, M. M., \& Hoy, W. (2001). A multilevel examination of the distribution and effects of teacher trust in students and parents in urban elementary schools. Elementary School Journal, 102(1), 3-17.

Heymann, S. J., \& Alison, E. (2000). Low-income parents: how do working conditions affect their opportunity to help school-age children at risk? American Educational Research Journal, 37(4), 833-848.

Lewis, A. E., \& Forman, T. A. (2002). Contestation or collaboration? A comparative study of home-school relations. Anthropology and Education Quarterly, 33(1), 60-89.

Lippitz, W., \& Levering, B. (2002). And now you are getting a teacher with such a long name. Science, 18(2), 205-213.

Mapp, K. L. (2003). Having their say: parents describe how and why they are engaged in their children's learning. School Community Journal, 13(1), 35-64.

Peisner, F., Ellen, S., \& Yazejian, N. (2002). Predicting parental perceptions of children's longitudinal school success from early child care experiences [Resumo]. In American Educational Research Association (Org.), Annual Meeting of the American Educational Research Association (p. 197). New Orleans: Autor.

Sankar-DeLeeuw, N. (2002). Gifted preschoolers: parent and teacher views on identification, early admission, and programming. Roeper Review, 24(3), 172-177.

Sheldon, S. B., \& Hopkins, J. (2002). The parents' social nets and convictions as predictors of parents' involvement. Elementary School Chicago, 102(4), 301-316.

Sigolo, S. R. R. L., \& Lollato, S. O. (2001). Aproximações entre escola e família: um desafio para educadores. In C. R. S. L. Chakur (Org.), Problemas da educação sob olhar da psicologia (pp. 37-65). Araraquara/ São Paulo: Laboratório Editorial/ Cultura Acadêmica.

Szymanski, H. (1997). Encontros e desencontros na relação família-escola. Idéias, 25, 213-225.

${ }^{1}$ Apesar de apenas um pai ter contribuído para a realização da entrevista, por questão de redação, alteraremos os termos pais e mães, no presente relato, visto uma das fontes de informação ter sido obtida através das observações do cotidiano familiar.

Valéria Aparecida Chechia, mestre e doutoranda em Psicologia pela Universidade de São Paulo, Ribeirão Preto, é professora na Faculdade de Educação São Luís (Jaboticabal, SP). Endereço para correspondência: Rua: Ariovaldo Esbaile, 490 (Jardim Nova Aparecida); Jaboticabal, SP; CEP: 14883-328. Tel.: (16) 32021265. E-mail valeriachehia@netsite.com.br Antônio dos Santos Andrade, doutor em Psicologia Escolar e do Desenvolvimento Humano pela Universidade de São Paulo, é professor no departamento de Psicologia e Educação da Universidade de São Paulo, Ribeirão Preto. E-mail: antandra04@yahoo.com.br 